\title{
Mollusks, Mortality, and Associated Myths
}

\section{Natalie L Davies ${ }^{1}$, Stephen W Davies ${ }^{2}$ and Jimmy T Efird ${ }^{3,4 *}$}

${ }^{1}$ Department of Medicine, Division of Dermatology, Brody School of Medicine, East Carolina University, Vidant Medical Center, Greenville, NC, USA ${ }^{2}$ Department of Surgery, University of Virginia School of Medicine, Charlottesville, VA

${ }^{3}$ Department of Cardiovascular Sciences, Brody School of Medicine, East Carolina University, East Carolina Heart Institute, Greenville, NC

${ }^{4}$ Center for Health Disparities, Brody School of Medicine, East Carolina University, Greenville, NC, USA

\section{Introduction}

Vibrio vulnificus has often been associated with tropical, third world geographical locations; however, certain regions of the United States may also experience such diseases and clinical practitioners need to be familiar with their diagnosis and treatment. Below, we provide a brief review on Vibro vulnificus, signs and symptoms of infection, diagnosis, treatment, recommendations on prevention, and 2 case reports to illustrate these points. Additionally, certain myths surrounding this bacterium are clarified.

\section{Background}

This organism was first described in 1976 by Reichelt et al. and named "Beneckea vulnifica" [1]. A subsequent first case series published in 1979 by Blake et al. reported 39 incident cases of human pathogenesis associated with a newly discovered, theretofore unnamed, lactose-fermenting Vibrio species designated L+ Vibrio [2]. The two designations were later discovered to belong to the same organism, which was later renamed Vibrio vulnificus [3].

Vibrio vulnificus is a gram-negative, rod-shaped, facultative anaerobic, halophilic organism found in warm seawater worldwide [4]. In the United States, it grows best when the water temperature is between $20^{\circ} \mathrm{C}$ and $30^{\circ} \mathrm{C}$ and thus grows better in the Gulf Coast than the cooler waters of the Atlantic and Pacific [5]. It most commonly resides in the tissues of oysters as a result of their filtration feeding [5]. One oysters may shed up to one million V. vulnificus cells per day [5]. People may become infected by ingestion of raw oysters (primary septicemia) or through wound contamination (secondary septicemia) from crabs, oyster shells, rocks, or other marine related sources typically during the warmer months between April and October. However, 40\% of documented cases occur from September through April [6].

\section{Signs and Symptoms}

Primary septicemia typically presents after ingestion of raw infected oysters. Approximately $10-20 \%$ of the United States population consumes raw shellfish at least once each year resulting in 95 reported cases of human infection, 85 hospitalizations, and 35 deaths annually $[5,7]$. If infected, patients may develop fever, chills, nausea, hypotensive shock, and formation of specific skin lesions (Figure 1) [8]. Skin lesions typically present as ecchymoses, characteristic hemorrhagic blisters, or necrotic ulcerations. These patients require prompt hospitalization and ICU care, as mortality risk is greater than $50 \%$ [7-9]. It is important to note that patients at greatest risk for this type of primary infection are typically middle-aged males with underlying disease (e.g., diabetes, malignancy, renal insufficiency, and liver disease) [9].

In secondary septicemia, pathogenesis occurs due to open wound contamination. A rapidly progressing cellulitis ensues with marked local swelling and hemorrhagic bullae (Figure 2) and may be accompanied by fever and chills [9]. Case fatality rates for this type of exposure are significantly lower at $15 \%$ [9]. Similar to primary septicemia, risk factors include chronic disease (e.g., liver and alcohol-related) [9] and immunocompromised state [7].

\section{Diagnosis and Treatment}

If infection is suspected, blood and wound or hemorrhagic blister fluid cultures should be immediately performed [7]. Treatment involves rapid initiation of antibiotics including doxycyline $(100 \mathrm{mg}$, IV or oral, twice daily for 7-14 days) and a third generation cephalosporin such as ceftazidine (1-2 g, IV every eight hours) [7]. Utilization of a single antibacterial agent such as fluoroquinolone (e.g., levofloxacin, ciprofloxacin, or gatifloxacin) may be as effective. In children, for whom doxycycline and fluoroquinolone are contraindicated, trimethoprimsulfamethoxazole plus an aminoglycoside are recommended. Additionally, necrotic tissue should be debrided [7].

\section{Recommendations}

Recommendations to reduce infection include avoiding raw seafood juice, raw oyster, and raw shellfish consumption altogether, but especially in immunocompromised individuals and those with liver disease. Contrary to common belief, the bacterium does not alter the taste, appearance, or odor of seafood and is not associated with human fecal waste or pollution [6,9]. Additionally, no amount of alcohol, hot sauce, or "months with the letter R" (i.e., September, October,

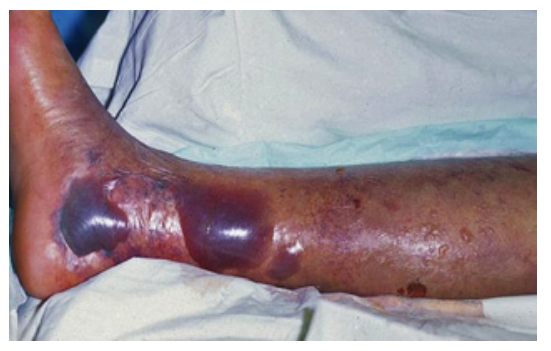

Figure 1: (Right Lower Extremity): A middle-aged, cirrhotic, Caucasian male after consuming raw oysters developed primary septicemia with large hemorrhagic blisters over lower extremities. Patient was treated with both doxycycline and ceftazidine, but rapidly progressed to septic shock and shortly thereafter expired.

*Corresponding author: Jimmy T Efird, Department of Public Health, Brody School of Medicine, East Carolina University, Physicians Quadrangle N, Greenville, NC 27834, USA, Tel: +1.650.248.8282; E-mail: jimmy.efird@stanfordalumni.org

Received August 08, 2013; Accepted September 20, 2013; Published September 25,2013

Citation: Davies NL, Davies SW, Efird JT (2013) Mollusks, Mortality, and Associated Myths. Trop Med Surg 1: 143. doi: 10.4172/2329-9088.1000143

Copyright: ( $) 2013$ Davies NL, et al. This is an open-access article distributed under the terms of the Creative Commons Attribution License, which permits unrestricted use, distribution, and reproduction in any medium, provided the original author and source are credited. 


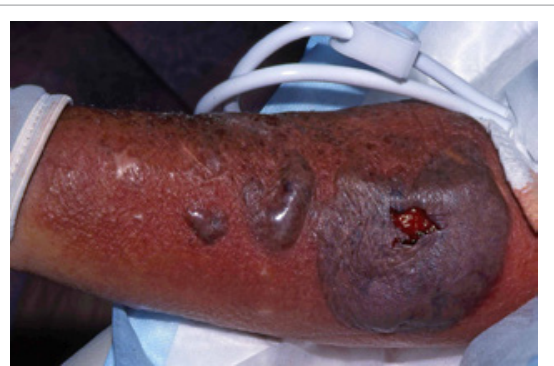

Figure 2: (Left Upper Extremity): A middle-aged Caucasian male on hemodialysis pinched by a crab in the Eastern North Carolina coast developed secondary septicemia with large hemorrhagic plaques and blisters on his forearm. Patient survived after receiving appropriate antibiotic treatment (i.e., doxycycline and ceftazidine) and resuscitation.

November, December, January, February, March, and April) will make the raw oysters any safer [6]. It also is important to refrigerate leftover seafood and to wear gloves when handling raw seafood; however, this does not ensure complete protection. People should avoid open wound exposure to seawater or wash exposed wounds immediately following with soap and water $[7,9]$.

\section{Acknowledgement}

This manuscript was funded in part by NIH grant (5T32AI078875-05). The authors would also like to acknowledge Drs. William A. Burke, Charles M. Phillips, and Robert G. Sawyer for their support and encouragement of this manuscript.

\section{References}

1. Reichelt JL, Baumann P, Baumann L (1976) Study of genetic relationships among marine species of the genera Beneckea and Photobacterium by means of in vitro DNA/DNA hybridization. Arch Microbiol 110: 101-120.

2. Blake PA, Merson MH, Weaver RE, Hollis DG, Heublein PC (1979) Disease caused by a marine Vibrio. Clinical characteristics and epidemiology. N Engl J Med 300: 1-5.

3. Farmer JJ 3rd (1979) Vibrio ("Beneckea") vulnificus, the bacterium associated with sepsis, septicaemia, and the sea. Lancet 2: 903.

4. Oliver JD (2005) Wound infections caused by Vibrio vulnificus and other marine bacteria. Epidemiology and infection 133: 383-391.

5. Bowers J, Dalsgaard A, DePaola A (2005) Risk Assessment of Vibrio vulnificus in raw oysters: Interpretative Summary and Technical Report: World Health Organization and Food and Agriculture Organization of the United Nations.

6. United States Food and Drug Administration. Raw Oyster Myths: Vibrio Vulnificus Health Education Kit.

7. Centers for Disease Control and Prevention. Vibrio vulnificus.

8. Bross MH, Soch K, Morales R, Mitchell RB (2007) Vibrio vulnificus infection: diagnosis and treatment. Am Fam Physician 76: 539-544.

9. Jones MK, Oliver JD (2009) Vibrio vulnificus: disease and pathogenesis. Infect Immun 77: 1723-1733. 